\title{
Treatment of afferent limb syndrome: novel approach with endoscopic ultrasound-guided creation of a gastrojejunostomy fistula and placement of lumen-apposing stent
}

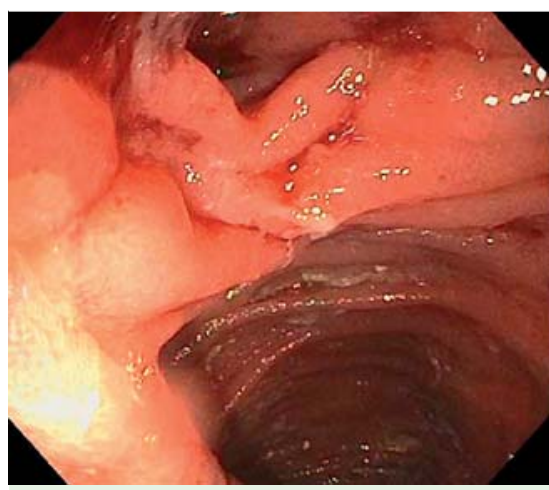

Fig. 1 Endoscopic view of gastrojejunostomy in a 44-year-old woman with recurrent pancreatic cancer after a Whipple procedure. The efferent limb is patent but the afferent limb is obstructed.

A 44-year-old woman, with recurrent pancreatic cancer after a Whipple procedure, presented with afferent limb syndrome that manifested as sepsis secondary to cholangitis thought to be due to obstruction of the Roux limb by tumor recurrence. Endoscopy revealed an obstruction of the afferent limb ( $\bullet$ Fig. 1 ) that could not be traversed with an endoscope or a guidewire under fluoroscopy. A dilated loop of small bowel was seen on endoscopic ultrasound (EUS) and was thought to be the obstructed afferent limb ( $\bullet$ Fig.2). A 19-gauge needle was inserted, contrast was injected ( $\bullet$ Fig.3) and a fistula was created. A $15 \mathrm{~mm} \times 10 \mathrm{~mm}$ lumen-apposing stent (Axios; Xlumena, Mountain View, California, USA) was deployed with the distal end in the afferent limb and the proximal end in the stomach ( Fig.4), with the intention of allowing further intervention as needed regarding the biliary tree. A single $7 \mathrm{Fr} \times 15 \mathrm{~cm}$ double-pigtail catheter was placed through the stent. The patient's cholangitis resolved and there were no complications. Given the tumor recurrence, the patient decided not to pursue further treatment and was lost to follow-up after choosing hospice care.

Afferent limb syndrome is a known complication following pancreaticoduodenectomy. In a retrospective review of 186 patients who underwent a Whipple

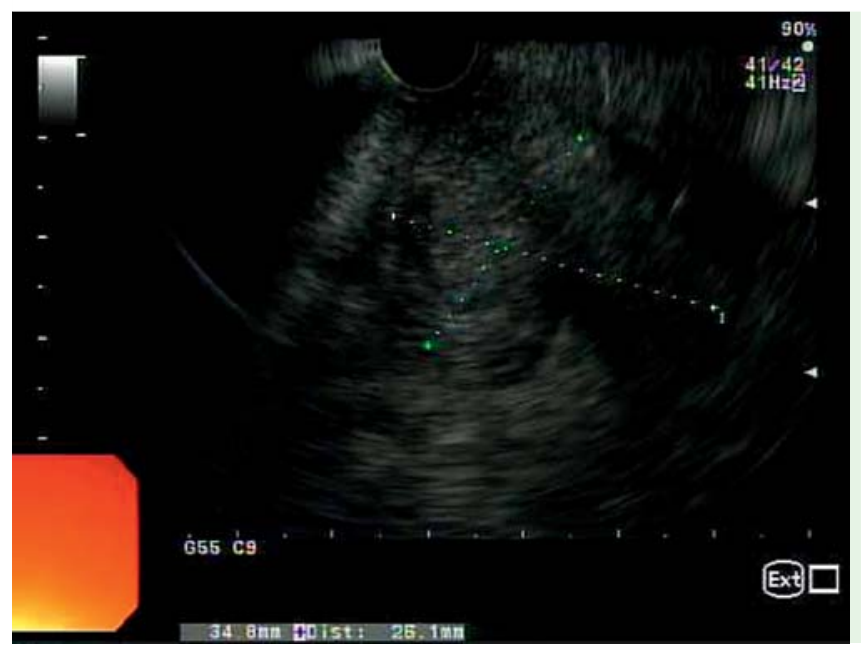

Fig. 2 Endoscopic ultrasound (EUS) view showing tumor recurrence. EUS also revealed a dilated loop of smallbowel consistent with afferent limb syndrome.
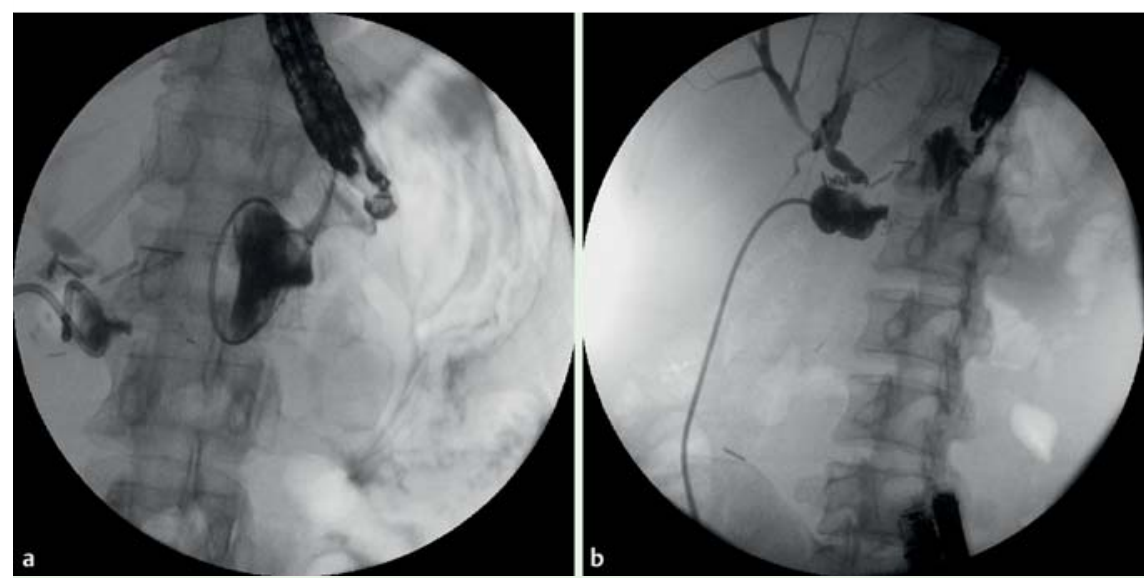

Fig. 3 Creation of the fistula. a Fluoroscopy shows placement of a wire into the afferent limb. $\mathbf{b}$ Contrast injected into the afferent limb shows opacification of the bile duct and stenosis. A percutaneous transhepatic cholangiography (PTC) tube that was previously placed in the afferent limb can be seen.

procedure, 13\% developed afferent limb syndrome [1]. Treatment options are limited and may require surgery or placement of a percutaneous transhepatic cholangiography tube.

Case reports have described successful endoscopic management of the obstruction with placement of stents across the stricture $[1,2]$. Pannala et al. described successful treatment in 15 patients with balloon dilation, stenting, or both [1]. However, endoscopic access to the afferent limb may not be possible because of long enteric segment, completely obstructing mass, tight angulation, or long stricture.
Successful endoscopic ultrasound (EUS)guided transgastric access into the afferent limb, with insertion of 7-Fr plastic stents and with no adverse events, has been described in case reports [4]. In the present case, we chose an Axios stent to take advantage of the intended wall apposition. The use of this stent has been described in pseudocyst drainage, gallbladder drainage, and creation of choledochoduodenal fistulas [5]. To our knowledge this is the first case of EUS-guided decompression with creation of a gastroenteric fistula using an Axios stent in a patient presenting with afferent limb syndrome. 

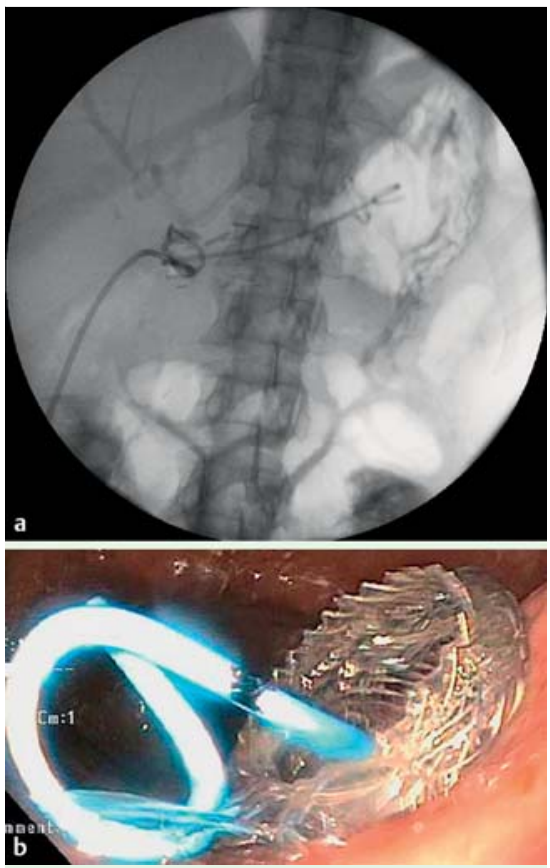

Fig. 4 Position of the lumen-apposing stent in the gastrostomy site. a The distal end is in the afferent limb, and a double-pigtail catheter has been placed. $\mathbf{b}$ Endoscopic view of the proximal end of the lumen-apposing stent (gastric side).
Given the feasibility, good outcome, and absence of complications in the case we describe, this may be a relatively safe and effective way of dealing with presentations of afferent limb syndrome.

\section{Endoscopy_UCTN_Code_CCL_1AC_2AH}

\section{Competing interests: None}

\section{Ashish Shah, Lauren Khanna, Amrita Sethi}

Department of Digestive and Liver Diseases, Columbia University Medical Center, New York, United States

\section{References}

1 Pannala R, Brandabur JJ, Gan SI et al. Afferent limb syndrome and delayed GI problems after pancreaticoduodenectomy for pancreatic cancer: single-center, 14 -year experience. Gastrointest Endosc 2011; 74: $295-$ 302

2 Burdick JS, Garza AA, Magee DJ et al. Endoscopic management of afferent loop syndrome of malignant etiology. Gastrointest Endosc 2002; 55: 602-605
3 Paulsen O, Skjennald A, Osnes M. An endoscopic drainage procedure for afferent loop occlusion. Gastrointest Endosc 1987; 33: $125-126$

4 Matsumoto K, Kato H, Tomoda T et al. A case of acute afferent loop syndrome treated by transgastric drainage with EUS. Gastrointest Endosc 2013; 77: 132-333

5 Binmoeller KF, Shah J. A novel lumen-apposing stent for transluminal drainage of nonadherent extraintestinal fluid collections. Endoscopy 2011; 43: 337-342

\section{Bibliography}

Dol http://dx.doi.org/

10.1055/s-0034-1392210

Endoscopy 2015; 47: E309-E310

(c) Georg Thieme Verlag KG

Stuttgart · New York

ISSN 0013-726X

\section{Corresponding author}

\section{Ashish Shah, MD}

Columbia University

Department of Digestive and Liver Diseases

161 Fort Washington Ave

HIP-8th Floor

New York 10032

United States

Fax: +01-212-305-1081

shahar3682@gmail.com 